\title{
Rethinking Technology in the Anthropocene: Guest Editors' Introduction
}

\author{
Pieter Lemmens ${ }^{1}$ - Yoni Van Den Eede ${ }^{2}$
}

Accepted: 11 December 2020 / Published online: 5 April 2021

(c) The Author(s), under exclusive licence to Springer Nature B.V. part of Springer Nature 2021

One of the defining moments in contemporary philosophy of technology was undoubtedly the 'empirical turn' of the 1990s and 2000s (Achterhuis 2001; Kroes and Meijers 2000; Franssen et al. 2016). Contra older, so-called transcendentalist, essentialist or "macrolevel" oriented approaches that had seen technology as an all-encompassing phenomenon or force, the empirical turn inaugurated more "micro-level" oriented analyses of concrete technologies, studied in their specific use contexts. Since a couple of years, however, the empirical turn has increasingly been called into question, with scholars asking whether it has not been pushed too far-certainly given recent technological developments that seem to give technology an all-encompassing or all-penetrating countenance (again): pervasive automation of all domains of society through AI (Artificial Intelligence) algorithms and (ro)bots, or the engineering grasp on life through nanotechnology, biotechnology and neurotechnology. Also, the ecological urgency characterizing our "Anthropocenic condition" appears to call for more broad-ranging perspectives than the mere analysis of concrete local use contexts. At the same time, nonetheless, the "empirical attitude" keeps demonstrating its usefulness for the philosophical study of technologies on a day-to-day basis... The question has been coming up more and more: Where do we go from here? Quo vadis philosophy of technology?

The contributions in this special issue all engage with this problematic. The collection of core papers originated in a two-day workshop that the guest editors put together on the themes just described, and that took place on January 10-11th, 2018 at Radboud University, Nijmegen, The Netherlands. The workshop itself, titled 'Philosophy of Technology at the Crossroads Again,' was envisioned as a unique encounter between two important "streams" in philosophy of technology, which literally took the form of a meeting between two key thinkers: Don Ihde and Bernard Stiegler, the latter of whom sadly passed away last year (on August 6th, 2020). Together with a select group of other philosophy of technology scholars, they set out to reflect upon points of convergence and divergence between their

Pieter Lemmens

p.lemmens@science.ru.nl

Yoni Van Den Eede

yoni.van.den.eede@vub.be

1 Radboud University, Nijmegen, The Netherlands

2 Centre for Ethics and Humanism, Free University of Brussels (Vrije Universiteit Brussel), Pleinlaan 2, 1050 Brussels, Belgium 
respective frameworks-postphenomenology in the case of Ihde and what may be called 'techno-phenomenology' and 'general organology' in the case of Stiegler-as well as on the near-future form that philosophy of technology should take, in a world struggling with multiple global crises - the planetary ecological crisis being the gravest and most challenging one.

In the aftermath of the workshop, we invited the speakers to expand upon their original papers, zooming in on two big thematic axes: the empirical-transcendental debate and the Anthropocene-which they all gracefully did. But we also enlarged the discussion by inviting more voices into the debate to comment, react and state their own positions visà-vis the original contributions. What lies before the reader is the harvest of this intensive and elaborate process of creative exchange and intellectual sparring, with no less than 33 contributors in total. In what follows, we want to set the stage for these conversations, by briefly sketching the stakes of the debates under concern and previewing in a nutshell the various viewpoints offered by the authors, thereby concentrating foremost on the authors responsible for the core papers.

\section{Technology with Capital "T" or Small " $t$ "}

The initial advocates of the empirical turn responded to what they thought to be the alltoo-monolithic and abstract character of so-called "classic" philosophy of technology, as instantiated in the work of for instance Heidegger, Jaspers, Ellul or Marcuse. These traditional approaches had typically theorized about technology in a broad and general sense, in terms of what is pejoratively called "'Technology" with a capital $T$ ' (Verbeek 2005, 4; original emphasis) or 'technology uberhaupt [sic]' (Ihde 2009, 22; original emphasis). Thereby, it was argued, they had largely neglected the role of concrete technical artifacts in shaping human behavior, experience, perception, cognition and all other forms of being-inthe-world. The turn toward analyzing specific technologies in specific contexts-technologies with a small " $t$ "- was meant to correct this oversight. Philosophy of technology, as illustrated by a famous chapter title of Andrew Feenberg, was at the crossroads, moving from essentialism to constructivism (Feenberg 2000).

Without doubt, the empirical turn, of which postphenomenology has been one of the most passionate defenders and representatives, has been very productive and has generated a plethora of insights into the various ways in which concrete technological innovations impact upon lifestyles and behavior patterns, and vice versa. Yet recently, more and more doubts have arisen about the turn: scholars inquire now whether we should at least partially re-turn to classic approaches, of course engaged with in a different way. There are two main reasons for this.

The first concerns a conceptual and methodological question: can empirical-turn perspectives make sufficient sense of the transcendental conditions of possibility of technology and technological culture as such - be they ontological, cultural-historical, politicoeconomic or even earth-systemic? A too-narrow focus on the concrete and the local, it is suggested, together with a refusal to view the processes of technologization from a wider angle and take account of the whole within which all specific technological developments take place (indeed up to the whole planet), runs the risk of losing view of the wider horizons and more encompassing developments within which our empirical analyses are executed. 
Incidentally, these horizons have tended to change rather dramatically in the last decades. That is the second reason. Technological innovation has become the key driving factor-and more and more a "disruptive," if not outright "destructive" one-of social and cultural evolution, and with the onset of the Anthropocene also ecological and geological evolution. We only have to mention things like AI, robotization, Big Data, the Internet of Things, human enhancement, virtual and augmented reality, social media, e-commerce, e-learning, cleantech, geoengineering, global surveying technology, ubiquitous (and even planetary-scale) computation, smart grids, smart cities, synthetic biology, biosystems genomics et cetera to make clear that humanity is currently in the grip of a technological upheaval that arguably dwarfs the ones that we now call the first and second Industrial Revolutions. Technologies nowadays acquire such a life- and globe-spanning character that it becomes pertinent again to ask about the capital " $T$ " aspect of technology.

All this calls for a renewed consideration of the empirical turn. Possibly we are in need of another turn that necessitates the rehabilitation - undoubtedly in a new sense-of "transcendentalist" and "wholist" concerns. Or are we? Whatever the answer to this question may prove to be, philosophy of technology is at the crossroads again.

\section{Two Key Figures, Two Streams}

The workshop at Nijmegen, from which this special issue came forth, endeavored to force a breakthrough in that impasse, as mentioned, by seeking to initiate a dialogue between two of the most prominent contemporary thinkers about technology, the American philosopher of technology Don Ihde and the recently deceased French philosopher and cultural critic Bernard Stiegler. The two of them represent essential "streams" within philosophy of technology of today, that are partly similar-rooting as they do in the same traditional sources (notably phenomenology and hermeneutics) - yet also divergent in their methodologies, critical dispositions, diagnostic focus and ultimate assessments of technology. In the context of the encounter, we also invited scholars familiar with the work of one or both of these philosophers to reflect on issues that were at stake in the debates currently held among their adherents, but in a more general sense also on issues coming up as a result of contemporary developments in technology, described above. Some of the scholars involved, moreover, had at that time already developed crucial positions on the "empirical turn debate" (cf. Scharff 2012; Smith 2015; Coeckelbergh 2017; Lemmens 2017b; 2017a; Van Den Eede, Goeminne, and Van den Bossche 2017; Zwier et al. 2016).

Although there are quite some similarities and affinities between the philosophical projects of Ihde and Stiegler, a serious dialogue between the two had never taken place up until that point. It was our conviction that such a dialogue could be very fruitful to both and even more so to those scholars who are influenced in one way or the other by either (or both) of these thinkers. Both Ihde and Stiegler developed, each in their own unique and original way, a phenomenological approach to technology by explicitly integrating the technical artifact into the very heart of the phenomenological enterprise. They do this not only by making it the principal object of phenomenological inquiry but also and more decisively by "technologizing" phenomenology in the sense of demonstrating technology's fundamental role in the constitution of the phenomena themselves, arguably granting technologies the status of 'the things themselves' that Husserl saw in the most basic phenomena of consciousness - phenomena that are themselves constituted, thus, by technology, as both Ihde and Stiegler show. 
Ihde has developed what he calls a postphenomenology and a material hermeneutics of human-technology relations (in particular, he distinguishes between embodiment, hermeneutic, alterity and background relations), as well as a concomitant cultural hermeneutics that maps technologies' cultural embeddedness. Stiegler forged what might be called a techno-phenomenology of temporality and historicity based on the idea of technology as an artificial retention, conditioning the retentional-protentional structure of human consciousness and Dasein more generally, and he developed an 'organology' as well as a 'pharmacology' of technics that conceptualizes the human condition as a fundamentally technical, i.e., thoroughly accidental condition in which psychosomatic organs, technical organs and social organisations constantly co-evolve. Although Stieglerian philosophy of technology mobilizes a broader variety of philosophical traditions in its thinking of the human-technology nexus than Ihde (including also psychoanalysis and deconstruction, for instance), its principal orientation remains phenomenological and, like Ihde's, his work is influenced most prominently by Husserl and Heidegger.

Both Ihde's and Stiegler's philosophical approaches offer a large panoply of conceptual tools to critically confront the aforementioned technological developments. Yet the approaches of these two leading authors/voices within contemporary philosophy of technology are also themselves explicitly open to "technological innovation," as it were. As Ihde declares at the end of his 2010 book Heidegger's Technologies: 'Philosophies of technology need to renew themselves constantly, just as the technologies themselves change' (Ihde 2010, 139). Stiegler for his part claimed that new technologies both enable and enforce new epistemes and new critical instruments for thought - specifically digital technologies. In this spirit we challenged Ihde and Stiegler and "their" scholars to engage in a mutually enriching reflection on the possible directions such a renewal should take, searching for common themes and concerns, against the backdrop of the rapidly evolving 'technosphere,' as Stiegler started to refer to it in his most recent writings (Stiegler 2018) or 'technium' (as Kevin Kelly (2011) calls it) that conditions our existence in ever more pervasive and intimate ways.

\section{Philosophy of Technology and the Anthropocene}

The theoretical and practical motivations for the encounter may be sufficiently clear by now, but we should not stop there. As suggested, we believe the envisioned discussion can also contribute in a pertinent way to another important debate: that of the Anthropocene. In our view, this wide-ranging "novelty" announcing itself at the horizon ever more dramatically is crucial to any future philosophy of technology. The new condition of the Anthropocene has made it imperative to think the Earth or rather the Earth system as the ultimate condition of possibility of all human activity whatsoever.

In the Anthropocene we can no longer regard the Earth exclusively as our technological civilization's 'standing reserve' (in Heidegger's famous terminology) or indispensible material and energetic resource base, and beyond that as nothing more than 'the inoperative scenery behind human operations,' in the words of the German philosopher Peter Sloterdijk (Sloterdijk 2018, 16). The Earth itself has become operative, indeed is starting to exhibit an agency of its own, as Bruno Latour has been arguing for some time now (Latour 2014), in response to human technological intervention. Renamed 'Gaia' not only by Latour (Latour 2017) but also by Isabelle Stengers (Stengers 2015), the Earth is intruding more and more in our technological civilizations, wreaking havoc 
on an ever larger scale; think only of the raging bush fires in the Amazon, Australia and California recently, or the rise of the sea level that will soon force people living in coastal cities to massively migrate inland. The Anthropocene Earth is becoming volatile, increasingly unstable, unpredictable and human-unfriendly, 'defiant' to use an expression of Clive Hamilton (Hamilton 2017). But foremost, according to a growing consensus among geologists and Earth system scientists, the human [anthropos] has now become the most influential and overwhelmingly destructive "geoforce" of the planet and will therefore be the crucial factor determining the future fate of the Earth's biosphere (barring its total collapse due to a global disaster), burdening it with an unprecedented responsibility for which it now seems to be completely unprepared, demanding a response-ability that it still doesn't possess.

This new and totally unprecedented geological and geotechnical situation is of the utmost relevance to philosophy of technology since it undoubtedly has enormous implications for the human-technology nexus or more broadly the human-nature-technology nexus. It calls for a radical renewal of philosophy of technology in our time. For these reasons we also made the Anthropocene a leading theme in the encounter between Ihde and Stiegler. Still today, we are convinced that their respective approaches offer plenty of opportunities to contribute to a future philosophy of technology "fit" for the Anthropocene. This will no doubt involve a "meeting between Phil-Tech and Eco-Phil," to paraphrase Ihde (Ihde 2002, 113ff.), but the most crucial explicit aim of the debate we intended to initiate was to reflect on common grounds between the thinking of Ihde and that of Stiegler, so as to confront and think the emerging "Anthropocenic condition" from the perspective of philosophy of technology.

Ihde already preluded on the notion of the Anthropocene in his groundbreaking 1990 book Technology and the Lifeworld, where he stated that 'the high magnificational powers of technology now carry geological impact' (Ihde 1990, 196) and that seeing 'technological civilization as a kind of biologically activated "geological" force,' interfering with the natural forces of Gaia, 'should by now be clear' (ibid., 202). Criticizing the 'dominantly expansionist ethic' (ibid., 197) of capitalist industrialization he then recommended a worldwide counter-ethic of conservation to guide technological innovation in the future. We may ask whether this was realistic given the inherent and ever accelerating expansionist thrust of our technological civilization or indeed the 'technosphere' (Haff 2013), which has shown no signs of slowing down until the current Covid-19 pandemic, and whether the "solution" should not be sought rather in imagining other, less destructive and less polluting forms of growth.

Stiegler gave the notion of the Anthropocene increasing prominence in his thinking about technology since he first embraced it at the General Organology conference organized by the Nootechnics collective in 2014 in Canterbury, UK. For Stiegler, briefly put, the Anthropocene is the concretization of what Heidegger called enframing and results from the generalized, global toxification and entropization of both the biosphere and the technosphere due to a careless and runaway capitalist industrialization that is in the process of completely automatizing and putting under calculational control all of human existence and beyond. For him, the Anthropocene is the Entropocene, caused by a technologically empowered humanity dangerously producing entropy and destroying diversity at all levels (biological, ecological, societal, ethnological, psychological, cultural, etc.). And the only answer to it is to strive for a negentropic turn-or bifurcation-in technological innovation so as to renew the production of planetary negentropy and diversity at all those levels, which will be necessary for staving off systemic collapse. 
Against this backdrop, obviously characterized here in the most concise way, we asked our speakers and the contributors to this special issue to reflect on the current status of the empirical versus transcendental debate and more generally on the question of how philosophy of technology should respond to its new planetary condition both geologically and technologically.

\section{A Note on Format and Process}

A short note on format and process is in place here. The issue was compiled through the "open peer commentary" system. This is an innovative take on peer review, where the classic (double) blind review procedure is replaced by open peer review: authors and reviewers see each others' names, but what is more, every step of the process is carefully edited and published as part of the issue. This gives a whole other dynamic to the academic discussion at hand. Put even more strongly, it opens up that debate in a way that is not usually shown by "standard" peer review. We thought that this format of discussion would ideally suit the issues under consideration, which truly concern the whole field of philosophy of technology (and beyond), and it would enable us moreover to involve many more perspectives and opinions in the debate. Important was that no single author should feel reservations about taking a controversial or subversive stance, and that the development of and struggle over ideas could take place fully out in the open.

Hence, the starting point of the special issue were the expanded papers of the participants of the original workshop (excluding, alas, Peter-Paul Verbeek who participated in the workshop but was not able to contribute to the issue). Those are the "core papers." Each of these were sent out to two referees, who wrote a commentary on the piece. Those two commentaries per paper were then distributed back to the "core" authors, who were invited to write a "final reply" to both of the reviewers' comments. All of those commentaries and replies are included in the issue.

\section{Overview}

The core papers, commentaries and final replies showcase a rich diversity of responses. For that reason, and because we believe the many different threads of thematic discussion should mainly speak for themselves, we have decided to restrict ourselves here to briefly outlining the themes of the core papers, in the hope that the reader will be able to thus gain at least a preliminary glance of what is on offer in this voluminous issue.

Mark Coeckelbergh argues that the empirical turn, though justified in principle as a correction to philosophy of technology's traditional transcendentalism, has gone too far in unduly neglecting the more holistic and transcendental concerns related to technology. In his paper he basically suggests a 'linguistic turn' for addressing these holistic and transcendental concerns, based principally on Wittgenstein's pragmatics of language games. The crucial role of language is hardly taken into account in contemporary philosophy of technology, in particular in postphenomenology. It is foremost language, Coeckelbergh shows in great detail and through many examples, that serves as a transcendental condition and mediator in all contexts of technology and technological change and it is also language that will play a decisive role as a transcendental condition for developing an answer to the 
challenge of the Anthropocene, even if the Earth itself appears increasingly as the ultimate 'transcendental' condition of possibility for humanity's technological endeavor.

Helena De Preester zooms in on what kind of human subjectivity typifies the Anthropocene. Typically in the context of the ecological crisis, the human subject is positioned as too much in the grip of consumerism and thus unable to live up to the the crisis' challenge. This inability is explained in psychological terms of, for instance, laziness, seduction and lack of knowledge. De Preester, through a meticulous and fine-grained argument resting on the work of such authors as Wark, Flusser and Pfaller, wants to show that the problem is not so much the purported shortcomings of the subject, but a deeper condition characterized by a profound ambivalence toward consumerism, that prevents one in fact from becoming a subject in the first place. We know we need to act, but we don't. Underlying this discrepancy between knowledge and behavior are 'illusions without owners'-Pfaller's notion-which De Preester analyzes as the conditions of possibility of that disconnect. This particularly characterizes subjectivity in the Anthropocene.

Yuk Hui does not engage explicitly with the theme of empirical versus transcendental, although he shows that whilst Ihde rejects the whole issue, Stiegler rethinks the transcendental divide in terms of what he calls 'a-transcendentality,' which means that all transcendental conditions are themselves vulnerable to being conditioned, in contrast to the unchanging and universal a priori conditions figuring in Kantian and later transcendentalist philosophy. Through an Erörterung à la Heidegger of our present planetary condition, Hui proposes as the answer to the Anthropocene what he calls a cosmotechnical turn of thinking about technology. Cosmotechnics refers to the unification between the cosmic order and the moral order through technical activities. Though building foremost on both Heidegger's and Stiegler's work, Hui's cosmotechnics perspective challenges the universalist view of technology still embraced by these authors and replaces it with a more pluralist and localist view of profound technodiversity which acknowledges the crucial importance of historical, cultural and geopolitical difference in the relations between the cosmos, morality and technical activities.

Don Ihde, in the combative spirit of the empirical turn, discusses how the transcendental 'push-back' in his view is largely Heideggerian in character, pointing out how Heidegger's 'high altitude' view of technology was modeled on industrial technology. Newer technologies, by contrast, are aimed toward micro and even nano processes. We thus need to adapt our philosophical understanding of technology accordingly, and that means, as Ihde also elaborated in earlier work, that the 'technodystopianism' of Heidegger can no longer form a useful starting point. Instead, we need detailed phenomenological and historical analyses and viewpoints, of which Ihde offers throughout his essay plenty of examples, in order to illustrate how Heidegger's 'industrial gigantism' has been overtaken by a 'post-Heideggerian nanoscale frontier technoscience.' In the process, Ihde also remarks upon how philosophical approaches may deploy mythological figures or narratives as origin stories (e.g., Stiegler's use of Prometheus and Epimetheus), but warns for this use of 'fictions,' instead wanting to opt for scientific starting points.

Pieter Lemmens defends the continuing relevance and usefulness - and therefore argues for the rehabilitation - of both transcendental approaches to technology and a wholistic conceptualization of technology in the sense of what most of mainstream philosophy of technology has discarded as 'Technology with a capital T,' doing so in particular through a critical assessment, from both a Heideggerian and Stieglerian perspective, of the views of postphenomenologists Ihde and Verbeek. He shows that this is particularly urgent in the emerging context of the Anthropocene in which it becomes more clear than ever that 
technology or technologized humanity is now a planetary force, indeed the crucial force responsible for the future course of the biosphere, an insight crystallizing currently in Earth system science with the introduction of the notion of the technosphere by Haff and others. With Stiegler it is shown that philosophy of technology should acknowledge an inherent and quasi-autonomous dynamic in the sense of 'Technology with a capital $\mathrm{T}$ ' in at least four ways: historically, anthropologically, techno-evolutionarily and (techno)phenomenologically. Yet it is especially the current planetary crisis that summons philosophy of technology to focus on technology's transcendental (i.e., overall conditioning) and wholistic dimension.

Robert C. Scharff approaches the problematic of the empirical versus transcendental in a genuine, originally Heideggerian spirit, from what he calls a 'pre-philosophical' standpoint, practicing some 'preparatory hermeneutics' by first asking from which position and with what concerns either empirically or transcendentally inclined philosophers respond to their life's experience in a technoscientific world. Through a reading of Nietzsche's famous second Untimely Meditations, On the Use and Disadvantage of History for Life, which engages with this pre-philosophical questioning more directly and pointedly than Heidegger himself, as well as through a dialogue with Feenberg, Scharff attempts to show that a vital, truly caring response to our technological condition in the context of the Anthropocene is conditional not so much upon objective knowledge, scientific information, philosophical theories etc., but on interpretation of pre-theoretical lived experience. As such he argues against an overly theoreticist approach to our predicament that he observes in both Ihde and Stiegler, irrespective of their empirical (Ihde) or transcendental (Stiegler) stance, and suggests a profoundly experiential approach, i.e., a philosophizing from experience rather than about it.

Dominic Smith already substantially reflected on the status of the empirical turn, making a plea for a renewed focus on the transcendental, in his book Exceptional Technologies and elsewhere. In the essay included in this volume he expands upon three important claims made in that book. First, he argues for discarding the pejorative connotations clinging to the term 'transcendental,' and thus for 'trivializing' it (meant obviously in a "good" way). Understood plainly as referring to conditions of possibility, inquiring into the transcendental — as an adjective, not as a reified domain — is the philosophical act. Second, Smith further elaborates his concept of 'exceptional technologies.' Those are 'limit cases' of technology that force us to reassess and reorient our understanding of technology, more precisely, digging into the conditions of possibility of exactly the received images, methods and concepts we use to delineate and study technology. This brings him, third, to a reconsideration of one of the central images that philosophy of technology has deployed to think about technology, namely, of the 'way' or 'road' - into which the images of a 'turn' (empirical turn) and a crossroad (cf. supra) of course play. Instead of 'road' imagery, he proposes to start thinking in terms of a 'multidimensional problem space.'

Bernard Stiegler offers an original re-interpretation of Heidegger's famous analysis of the essence of technology through the notions of enframing, the danger, the turning and the event, based on his own organological and pharmacological understanding of humanity's technical condition. To exit the Anthropocene, which he apprehends as the Entropocene or the age of generalized toxicity and entropization of the biosphere by the global industrial system annexed by capital, and to 'bifurcate' in what he calls the Neganthropocene, we need to break with the nihilist totalization of efficient causality typical of today's reign of calculation and all-out-automatization and restore final causality. This requires a re-thinking, though, of both these causalities in terms of what Deleuze has called quasi-causality, which is what Stiegler attempts in his article through a detailed re-reading of Aristotle's 
theory of four causes as it is employed by Heidegger in his analysis of technology. In this re-reading, quasi-causality is thought of as a confrontation by humans of the ordeal of the truth of enframing as the danger so as to make it true as their original and necessary default.

Yoni Van Den Eede's essay reviews the empirical-transcendental debate, zooming in on the role postphenomenology has played in it and finding how the debate has gradually acquired-perhaps because of the sheer fact of it being a debate and along the way having been reified to a certain extent-something of a stalemate character, with two positions pitted against each other and the two opposing factions seemingly not budging an inch. Attempting to find another way into the issues at stake, with an eye on reorienting and opening up the debate, he turns to object-oriented ontology (OOO), specifically the work of Harman and Morton, to explore ways of bridging the purported gap between the positions of "technology with a small "t"" and "Technology with a capital "T." The result is an OOO-inspired multiplication of the transcendental-empirical relation, extending it to all interactions between things. Certainly in times of algorithmic technologies, such a move makes sense and almost as a gracious side effect, by that move, the transcendentalempirical debate becomes all of a sudden much less threatening. In closing, Van Den Eede inquires into what this may mean for postphenomenology and for our thinking of/about the Anthropocene.

Galit Wellner dives straight into a hands-on comparison of the work of Ihde and of Stiegler, focusing on the themes of AI and imagination. Do AI algorithms, as they produce artworks, music etc., partake in imagination, and how does this process impact on human imagination? These are highly interesting questions as such, but Wellner finds an innovative inroad into the issue by combining Ihdean and Stieglerian perspectives. While Ihde connects imagination to perception, Stiegler connects it to memory, she observes. Synthesizing both, Wellner proposes, gives us an account of imagination that no longer, as in the 'modernist' view, regards imagination as the generation of 'new points of view.' 'Digital imagination,' by contrast, as mediated by algorithms, works in layers, and what AI algorithms do is 'fill in' the layers with data, thus producing 'endless' possibilities (or variations) out of which humans can choose. This is how algorithms and humans can work together, with the human still needed in the process to create meaning. Instead of opting for dystopian imagery of the machines "overtaking," Wellner offers a constructive stance that expects humans in the (near) future to further adapt to working with algorithms, which will take our imagination in unexpected directions.

Hub Zwart focuses not only on thinking about technology but also about the technosciences in the context of the Anthropocene. And the approach to assess developments in technology and the technosciences that he suggests is still viable for the Anthropocene age, is dialectics. Building on Hegelian dialectics, he thus develops a dialectical method for understanding but also evaluating how contemporary technological innovation and technoscientific research proceeds against the backdrop of disruptive technological and environmental change. The new dialectics he proposes operates in close proximity and interaction with the concrete research practices of scientists and engineers but focuses on the conceptual level, tracing how research gives rise to new views on life, nature and technology (and their interrelationship). Taking the current project to build a synthetic cell from scratch in the life sciences as case study, he extensively illustrates how this dialectics functions and also reflects on the question of how to assess such a project: as ultimate exemplification of the will to power and the desire to fully control life, or as an attempt to come to a more benign co-existence of nature and technology in the Anthropocene future, or both? 
This concludes our overview of the core papers. The reader is strongly advised, after having assimilated these thought-provoking contributions, to delve into all the commentaries and final replies. An adventurous and stimulating intellectual journey is promised.

One tremendously sad event threw a shadow over this journey, in the final stages of producing the issue. In the summer of 2020, we received the tragic news of Bernard Stiegler's passing. Unfortunately at that time Bernard had not been able to finish his final reply to the two excellent commentaries on his core paper by Vincent Blok and Alexander Wilson. We thought it fitting, as a farewell and intellectual tribute-and in consultation with Foundations of Science's Editor-in-Chief-to include instead of his final reply an obituary piece, written by Pieter Lemmens.

We dedicate this special issue to Bernard Stiegler's memory and legacy.

\section{References}

Achterhuis, H. (Ed.). (2001). American philosophy of technology: The empirical turn. Translated by Robert P. Crease. Bloomington: Indiana University Press.

Coeckelbergh, M. (2017). Using words and things: Language and philosophy of technology. New York: Routledge.

Feenberg, A. (2000). From essentialism to constructivism: Philosophy of technology at the crossroads. In E. Higgs, A. Light, \& D. Strong (Eds.), Technology and the good life? (pp. 294-315). Chicago: The University of Chicago Press.

Franssen, M., Vermaas, P. E., Kroes, P., \& Meijers, A. W. M. (Eds.). (2016). Philosophy of technology after the empirical turn. Cham: Springer International Publishing.

Haff, P. (2013). Technology as a geological phenomenon: Implications for human well-being. Geological Society London Special Publications, 395(1).

Hamilton, C. (2017). Defiant earth: The fate of humans in the Anthropocene. Cambridge: Polity.

Ihde, D. (1990). Technology and the lifeworld: From garden to earth. Bloomington: Indiana University Press.

Ihde, D. (2002). Bodies in technology. Minneapolis: University of Minnesota Press.

Ihde, D. (2009). Postphenomenology and technoscience: The Peking University lectures. Albany (NY): State University of New York Press.

Ihde, D. (2010). Heidegger's technologies: Postphenomenological perspectives. New York: Fordham University Press.

Kelly, K. (2011). What technology wants. New York: Viking.

Kroes, P., \& Meijers, A. (Eds.). (2000). The empirical turn in the philosophy of technology. Amsterdam: JAI.

Latour, B. (2014). Agency at the time of the Anthropocene. New Literary History, 45, 1-18.

Latour, B. (2017). Facing Gaia: Eight lectures on the new climatic regime. Translated by Catherine Porter. Cambridge: Polity.

Lemmens, P. (2017a). Love and realism. Foundations of Science, 22(2), 305-310. https://doi.org/10. 1007/s10699-015-9471-6.

Lemmens, P. (2017b). Thinking through media: Stieglerian remarks on a possible postphenomenology of media. In Y. Van Den Eede, S. O. Irwin, \& G. Wellner (Eds.), Postphenomenology and media: Essays on human-media-world relations (pp. 185-206). Lanham: Lexington Books.

Scharff, R. C. (2012). Empirical technoscience studies in a Comtean world: Too much concreteness? Philosophy and Technology, 25(2), 153-177. https://doi.org/10.1007/s13347-011-0047-2.

Sloterdijk, P. (2018). What happened in the twentieth century? Towards a critique of extremist reason. Translated by Christopher Turner. Cambridge: Polity.

Smith, D. (2015). Rewriting the constitution: A critique of 'postphenomenology.' Philosophy and Technology, 28(4), 533-551. https://doi.org/10.1007/s13347-014-0175-6.

Stengers, I. (2015). In catastrophic times: Resisting the coming barbarism. Translated by Andrew Goffey. London: Open Humanities Press.

Stiegler, B. (2018). Qu'appele t'on panser 1. L’immense régression. Paris: Les Liens qui Libèrent. 
Van Den Eede, Y., Goeminne, G., \& Van den Bossche, M. (2017). The art of living with technology: Turning over philosophy of technology's empirical turn. Foundations of Science, 22(2), 235-246. https://doi.org/10.1007/s10699-015-9472-5.

Verbeek, P.-P. (2005). What things do: Philosophical reflections on technology, agency, and design. Translated by Robert P. Crease. University Park (PA): The Pennsylvania State University Press.

Zwier, J., Blok, V., \& Lemmens, P. (2016). Phenomenology and the empirical turn: A phenomenological analysis of postphenomenology. Philosophy and Technology, 29(4), 313-333. https://doi.org/10. 1007/s13347-016-0221-7.

Pieter Lemmens teaches philosophy and ethics at the Institute for Science in Society (ISiS), Radboud University, Nijmegen, The Netherlands. He has published on themes in the philosophy of technology and new media and on human enhancement technologies, on the work of Martin Heidegger, Peter Sloterdijk and Bernard Stiegler, on the Anthropocene as well as on post-operaist Marxism (Hardt, Negri, Berardi) and topics related to philosophical anthropology and phenomenology. Current interests include the philosophy of technology in the age of the Anthropocene and the notion of the technosphere. His articles have appeared in journals such as Techne, Philosophy \& Technology, Foundations of Science, Human Studies, Angelaki, Krisis, The Journal of Agricultural and Environmental Ethics, Tijdschrift voor Filosofie and Boundary2. He translated Bernard Stiegler's Philosopher par accident in Dutch (2014), co-edited a book on the philosophy of landscape and place (2011), plus a volume on contemporary German philosophy, both in Dutch (2013), and together with Yuk Hui he published the edited volume Cosmotechnics. For a Renewed Concept of Technology in the Anthropocene (Routledge, forthcoming in June 2021). He currently prepares an introductory book on the philosophy of technology, to appear mid 2021 (Boom publishers), as well as a monograph on the work of Bernard Stiegler.

Yoni Van Den Eede is senior researcher and lecturer affiliated with the Centre for Ethics and Humanism at the Free University of Brussels (VUB). He conducts research into the philosophy of technology and media, media ecology and philosophy of culture, with an emphasis on phenomenological, cultural, existential, political and ethical themes. He is the author of among others The Beauty of Detours: A Batesonian Philosophy of Technology (SUNY Press, 2019) and Amor Technologiae: Marshall McLuhan as Philosopher of Technology (VUBPRESS, 2012). He has (co-)edited among others special issues of Techné: Research in Philosophy and Technology, Foundations of Science and Explorations in Media Ecology as well as the book Postphenomenology and Media: Essays on Human-Media-World Relations (Lexington Books, 2017). Since 2011 he is a member of the Board of Directors of the Society for Phenomenology and Media, and from 2014 to 2016 he served as President of that same organization. 